\title{
Reduction of Zinc Oxide Sinter by Carbon Monoxide Gas
}

\author{
Takahiko Okura* \\ Nikko Techno Service Co., Ltd. Minato-ku, \\ Tokyo 105-0001, Japan
}

(Received January 12, 2002; final form February 18,2002)

\begin{abstract}
Reduction experiments of zinc oxide sinter in carbon monoxide gas have been carried out in the temperature range of 1073-1473 $\mathrm{K}$, and reduction mechanism and reaction rate-controlling step were discussed. The activation energy for reduction of zinc oxide sinter by carbon monoxide gas is estimated to be $124 \mathrm{~kJ} / \mathrm{mole}$ at temperatures below $1273 \mathrm{~K}$ and $146 \mathrm{~kJ} / \mathrm{mole}$ at temperatures above $1323 \mathrm{~K}$, respectively, and the overall activation energy of diffusion is estimated to be $341 \mathrm{~kJ} / \mathrm{mole}$.
\end{abstract}

\section{INTRODUCTION}

In the electrothermic distillation process for zinc, zinc oxide sinter (hereafter referred to as the sinter) is reduced to zinc vapor by metallurgical coke and the heating energy generated by electricity. The reaction in furnace may be expressed by

$$
\mathrm{ZnO}+\mathrm{C}=\mathrm{Zn}(\mathrm{g})+\mathrm{CO}
$$

However, it is quite likely to be accompanied by the following two reactions: the indirect reduction by carbon monoxide gas ( $\mathrm{CO}$ gas) and the carbon solution loss reaction.

$$
\mathrm{ZnO}+\mathrm{CO}=\mathrm{Zn}(\mathrm{g})+\mathrm{CO}_{2}
$$

$$
\mathrm{C}+\mathrm{CO}_{2}=2 \mathrm{CO}
$$

The reduction mechanism and rate-controlling step of the reaction of the sinter with $\mathrm{CO}$ gas should be clearly explained in order to facilitate the better understanding of this process.

The activation energy of pure $\mathrm{ZnO}$ is estimated to be $86 \mathrm{~kJ} / \mathrm{mole} / 1 /$. On the other hand, the purpose of this work is to present the results for the sinter actually charged into the production furnace. The reduction experiments were carried out in the temperature range between 1073 and $1473 \mathrm{~K}$. The un-reacted core model was tested on the basis of the cross-sectional photographic observation of the reduced residues, and a new kinetic model was proposed. Using this model, the rate-controlling step was also discussed.

\section{EXPERIMENTS}

\subsection{Materials}

The sinter was prepared by a sintering machine and was crashed down to a size of $6.5 \sim 7.5 \mathrm{~mm}$ in diameter. The chemical composition of samples presently used is summarized in Table 1.

\subsection{Experimental procedures}

Figure 1 shows the schematic diagram of the experimental apparatus. Several sinters are placed as a single layer and separately to each other on the stainless

\footnotetext{
'Corresponding author, email address:okura@nikko-metal.co.jp
} 


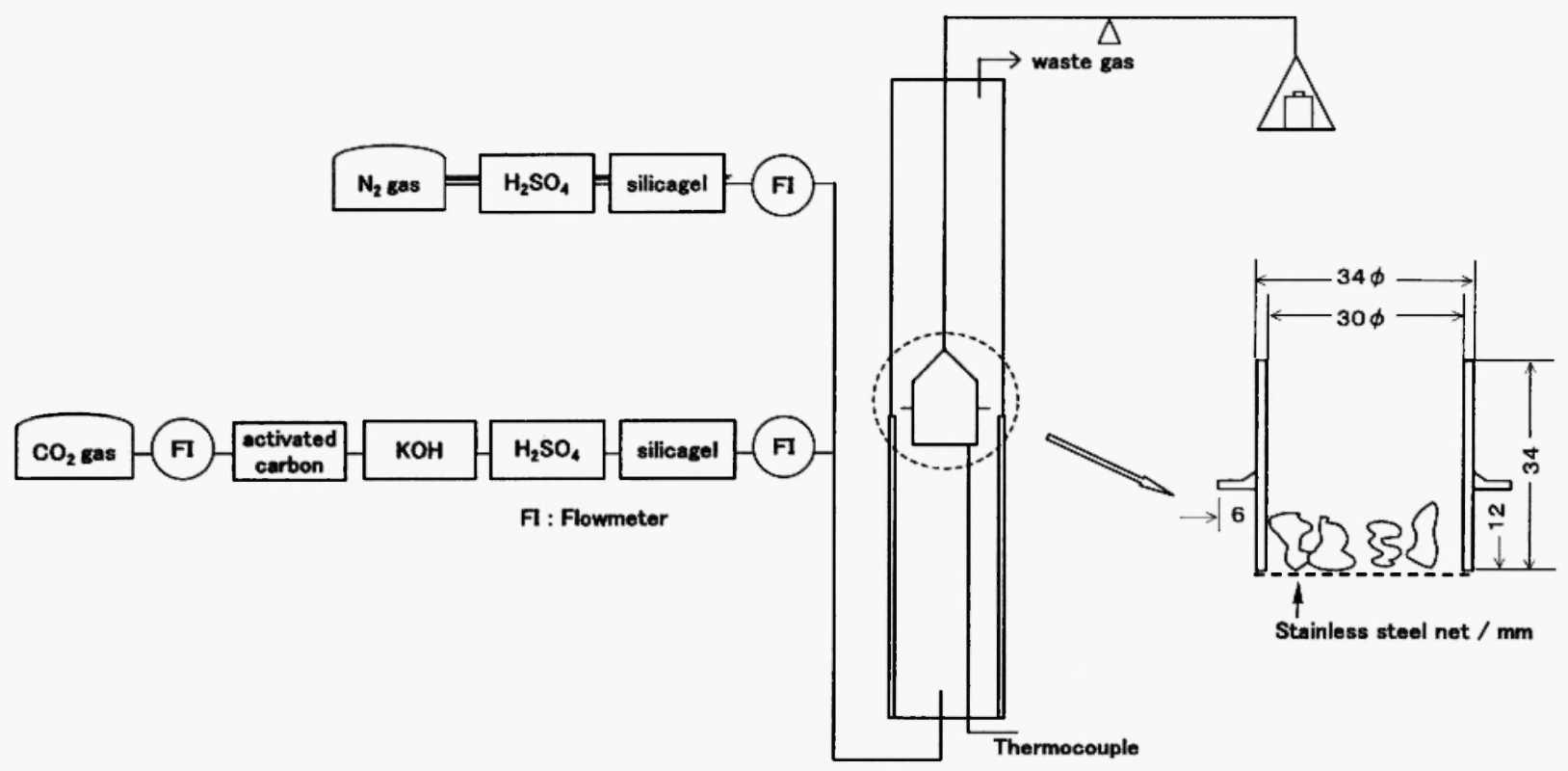

Fig. 1: Schematic diagram of the experimental apparatus

Table 1

Chemical composition of the samples used in this work

\begin{tabular}{|l|l|l|l|l|l|l|l|l|}
\hline $\mathrm{Zn}$ & $\mathrm{T}-\mathrm{Fe}$ & $\mathrm{M}-\mathrm{Fe}$ & $\mathrm{Fe}(\mathrm{ll})$ & $\mathrm{Fe}(\mathrm{lll})$ & $\mathrm{SiO}_{2}$ & $\mathrm{CaO}$ & $\mathrm{Pb}$ & $\mathrm{Cd}$ \\
\hline 55.5 & 9.65 & 0.35 & 0.55 & 8.75 & 7.7 & 3.30 & 0.99 & 0.020 \\
\hline $\mathrm{Cu}$ & $\mathrm{Mn}$ & $\mathrm{As}$ & $\mathrm{ln}$ & $\mathrm{Ag}$ & $\mathrm{S}$ & $\mathrm{Al}_{2} \mathrm{O}_{3}$ & $\mathrm{Mg}$ & \\
\hline 0.385 & 0.87 & 0.069 & 0.028 & 0.019 & 0.01 & 2.005 & 0.455 & \\
\hline
\end{tabular}

steel net in the reaction tube, which is heated by an electrical furnace, and the $\mathrm{CO}$ gas is fed from downward. The preliminary experiments confirmed that the reduction rate evaluated from the weight change is close to the value obtained from the chemical analysis method. Thus, the reduction degree is evaluated from the change in sample weight in this work. The $\mathrm{CO}$ gas is generated by the reaction with activated carbon and $\mathrm{CO}_{2}$ gas and is purified through the columns of $\mathrm{KOH}$ and $\mathrm{H}_{2} \mathrm{SO}_{4}$ solution. The flow rate of the mixture of $\mathrm{CO}$ and $\mathrm{N}_{2}$ gas is set at $5 \mathrm{Nl} / \mathrm{min}$ based on the preliminary experiment indicating that the flow rate higher than $4 \mathrm{~N} 1$ /min should be kept for steady reaction.

\section{RESULTS AND DISCUSSION}

\subsection{Effect of $\boldsymbol{P}_{\text {Co }}$ on the reduction rate}

The order of the reaction should first be determined for further discussion. Figure 2 shows the reduction rate as a function of partial pressure of $\mathrm{CO}$ gas $\left(P_{\mathrm{CO}}\right)$. As seen in Fig. 2, the rate varies linearly as a function of $P_{\mathrm{CO}}$, and then the reaction can be described by the first order.

\subsection{Effect of reduction temperature}

The effect of reduction temperature on the rate is shown in Fig. 3. The rate becomes faster according to 


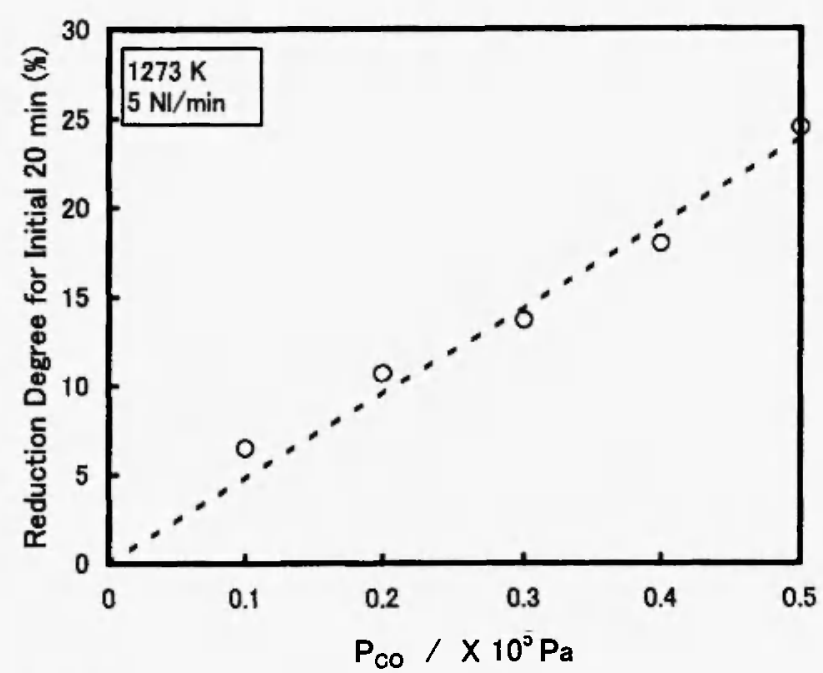

Fig. 2: Relation between initial reduction rate and $P_{C O}$

the temperature rise in the range of 1073-1273 K (hereafter referred to as low reduction temperature). However, the rate at $1323 \mathrm{~K}$ is lower than that at 1073 $K$. Then it increases with increasing reduction temperature (hereafter referred to as high reduction temperature), finally the rate at $1473 \mathrm{~K}$ is found to be almost the same as that at $1273 \mathrm{~K}$.

\subsection{Cross-sectional observation of reduction residue}

Figure 4 shows the cross-sectional photograph of the reduced sample at $1273 \mathrm{~K}$ for $60 \mathrm{~min}$, corresponding to the low reduction temperature. The reaction is found to proceed to keep the same pattern of the reaction interface as the outer profile of the original sinter, and it suggests that the un-reacted core model may be applied to the results. At high reduction temperature, the third layer as well as the fused reduced residue were observed. The changes in rate at both low and high reduction temperatures are attributed to a decrease in the $\mathrm{CO}$ gas fraction diffused to the reaction interface owing to the fusion of the reduced residue.

\subsection{Analysis by an un-reacted core model}

The following three assumptions were used to derive the model as follows.

(1) The reaction is steady and consecutive.

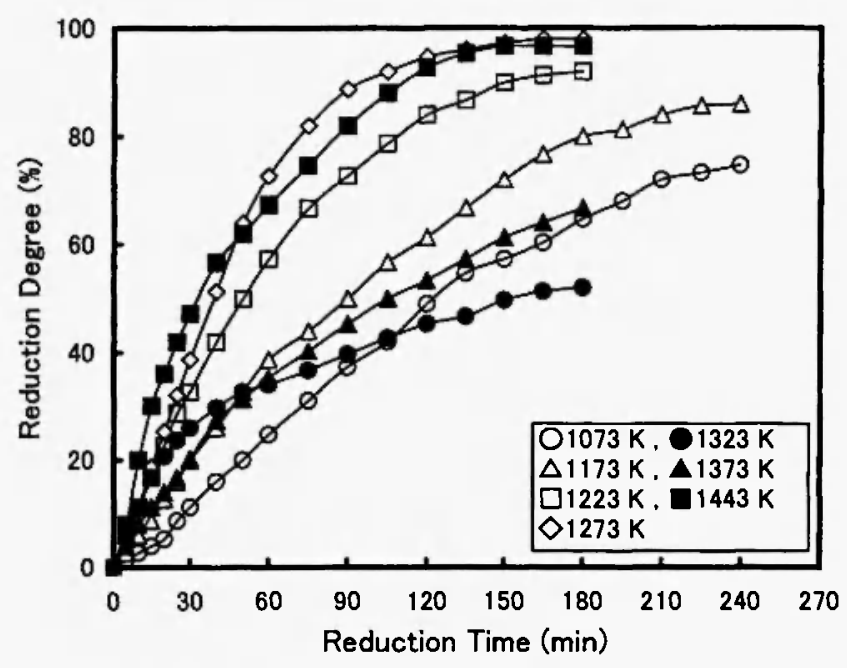

Fig. 3: Effect of reduction temperature on the rate

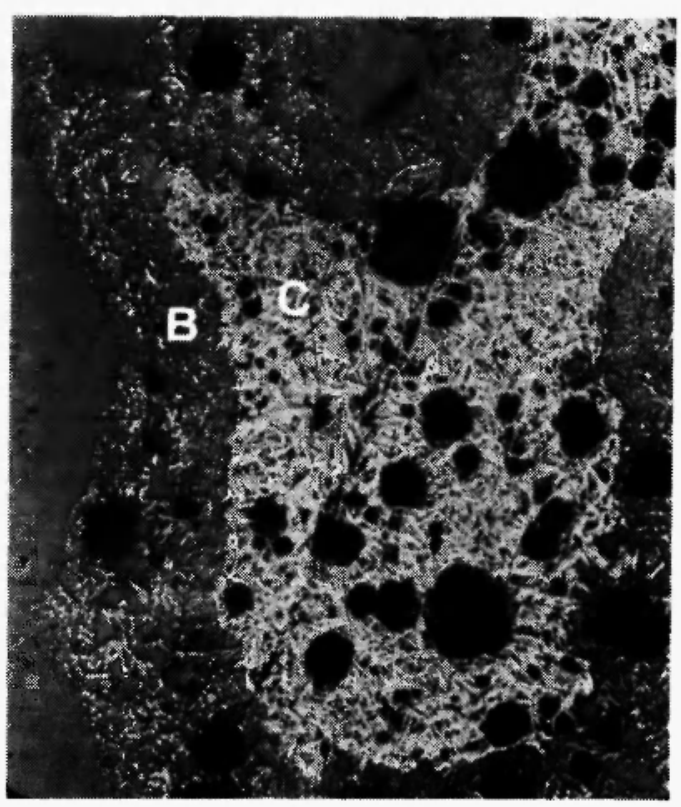

Fig. 4: Photograph of cross-section of reduced sample $(1273 \mathrm{~K}, 60 \mathrm{~min})$. (B; reduced layer, $\mathrm{C}$; zinc oxide)

(2) The reaction is the first order and irreversible, and its rate is proportional to the concentration of $\mathrm{CO}$ gas at the reaction interface.

(3) The mixed gas system of $\mathrm{CO}-\mathrm{CO}_{2}-\mathrm{Zn}(\mathrm{g})-\mathrm{N}_{2}$ is considered ideal. 
Equations (4), (5) and (6) express molar fluxes, $n_{j}$ $\left(\mathrm{j}=\mathrm{CO}, \mathrm{CO}_{2}, \mathrm{Zn}(\mathrm{g})\right.$ ) through the gas layer outside of the sinter, through the reduced residue layer, and the chemical reaction at the interface, respectively;

$$
\begin{aligned}
& -n_{j}=4 \pi R^{2} \cdot k_{g} \cdot\left(C_{j}^{h}-C_{j}^{s}\right) \\
& n_{j}=4 \pi D_{j}^{c} \operatorname{Rr}\left(C_{j}^{s}-C_{j}^{i}\right) /(r-R) \\
& -n_{Z n O}=4 \pi r^{2} \cdot k \cdot\left(C_{C O}^{i}-C_{C O}^{*}\right)^{10}= \\
& 4 \pi r^{2} k\left(C_{C O}^{i}-\frac{P^{i} \cdot C_{C O 2}^{i} \cdot C_{Z n}^{i}}{K \cdot C_{T}^{i}}\right)
\end{aligned}
$$

where $R$ is the initial radius of the sinter, $k_{\mathrm{g}}$ the mass transfer coefficient, $C_{1}$ concentration of $\mathrm{j}$ species in the bulk (b), at the surface of the sinter (s) and at the interface (i), $\mathrm{r}$ the unreacted core radius, $D_{\mathrm{j}}^{\mathrm{c}}$ the diffusion coefficient through the reduced residue layer, $\mathrm{k}$ the rate constant of chemical reaction, $C_{\mathrm{T}}$ the total molar concentration in the gas phase, $K$ the equilibrium constant for the reaction of eq.(2), $P$ the total pressure in the gas phase, the equilibrium state.

By combining eqs. (4), (5) and (6), the following relation can be obtained:

$$
t=\frac{R d_{0}}{C_{C O}^{b}}\left\{\frac{1}{3 k_{g}} n_{2:}+\frac{R}{6 D_{C O}^{e}}\left(3 f^{2}-2 f^{3}\right)+\frac{1}{k} f\right\}
$$

where $t$ is the reduction time, $R_{\mathrm{X}}$ the reduction degree, $f$ $=1-\left(1-R_{\mathrm{X}}\right)^{1 / 3}$.

When the chemical reaction at the interface is assumed to be the rate-controlling step, the following equation is readily obtained:

$$
t-t_{f}=\frac{R_{0}}{C_{C u}^{b}} \frac{1}{k} f
$$

where $t_{\mathrm{f}}$ corresponds to the first term of the left side of eq.(7). The relation is also obtained for the mixed rate-controlling step by chemical reaction and gas diffusion through the reduced residue layer.

$$
\frac{t-t_{f}}{f}=\frac{R^{2} d_{0}}{6 C_{C O}^{h}} \frac{1}{D_{C O}^{t}}\left(3 f-2 f^{2}\right)+\frac{R d_{0}}{C_{C O}^{b}} \frac{1}{k}
$$

\subsection{Reduction mechanism}

The experimental results at low reduction temperature are shown in Fig. 5. Good linearity is found even in the higher reduction degree case and it suggests that chemical reaction can be described by the ratecontrolling step at temperatures below $1273 \mathrm{~K}$.

On the other hand, the experimental results at temperatures higher than $1323 \mathrm{~K}$ are reproduced by the relation for the mixed rate-controlling step by chemical reaction and gas diffusion through the reduced residue layer, as shown in Fig. 6. It may be safely said that the mixed rate-controlling step is considered dominant in the temperature range above $1323 \mathrm{~K}$.

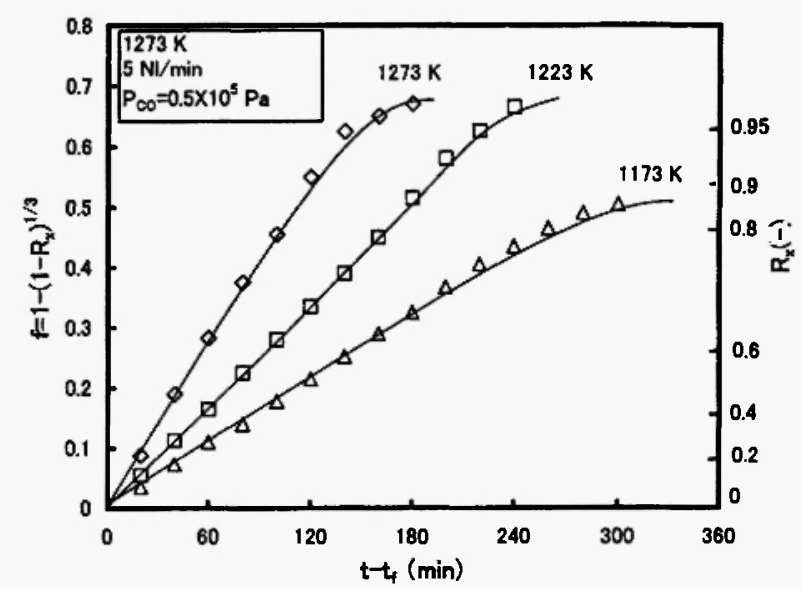

Fig. 5: Rate-controlling step of chemical reaction at low reduction temperature

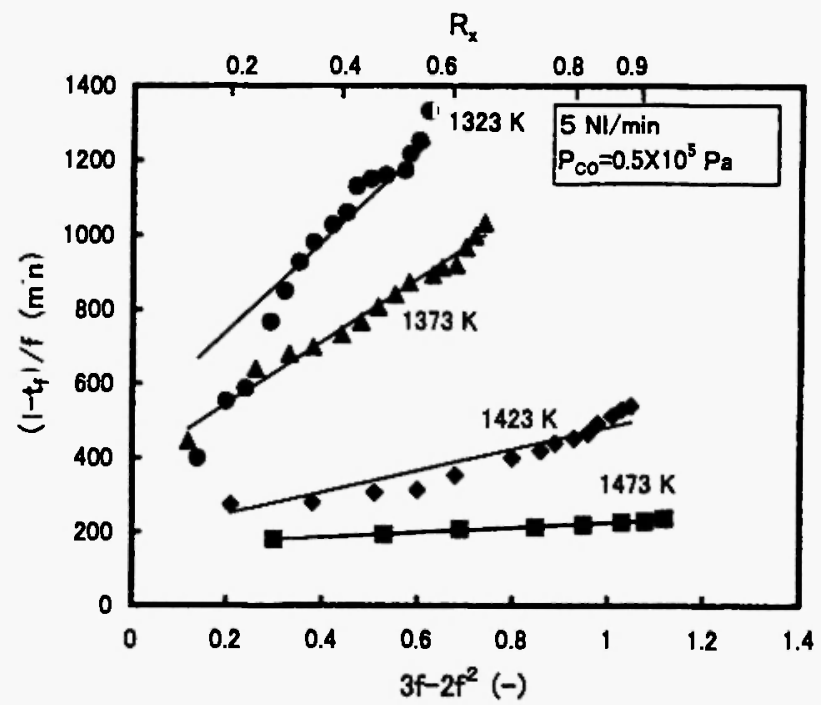

Fig. 6: Rate-controlling step of the mixed chemical reaction and gas diffusion at high reduction temperature 


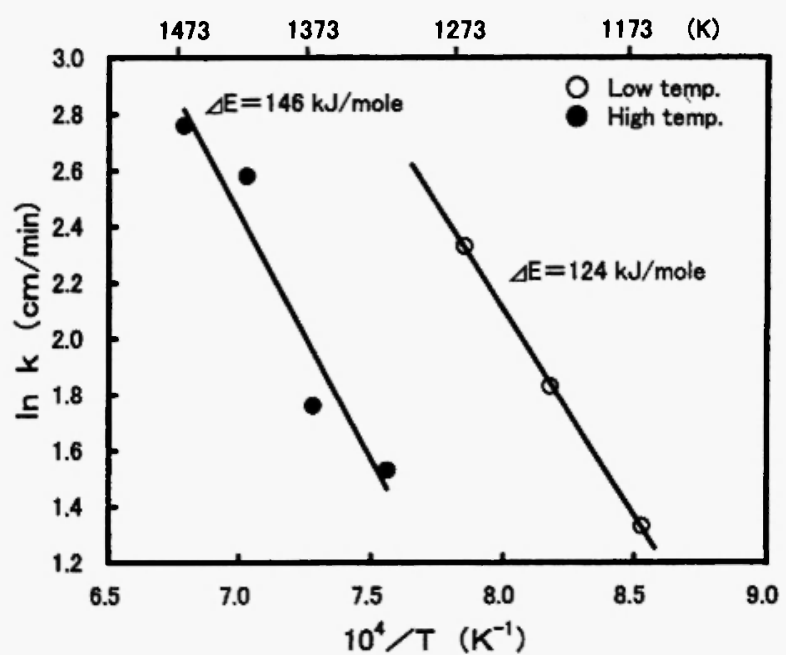

Fig. 7: The relation of $\ln (k)$ and $1 / T$

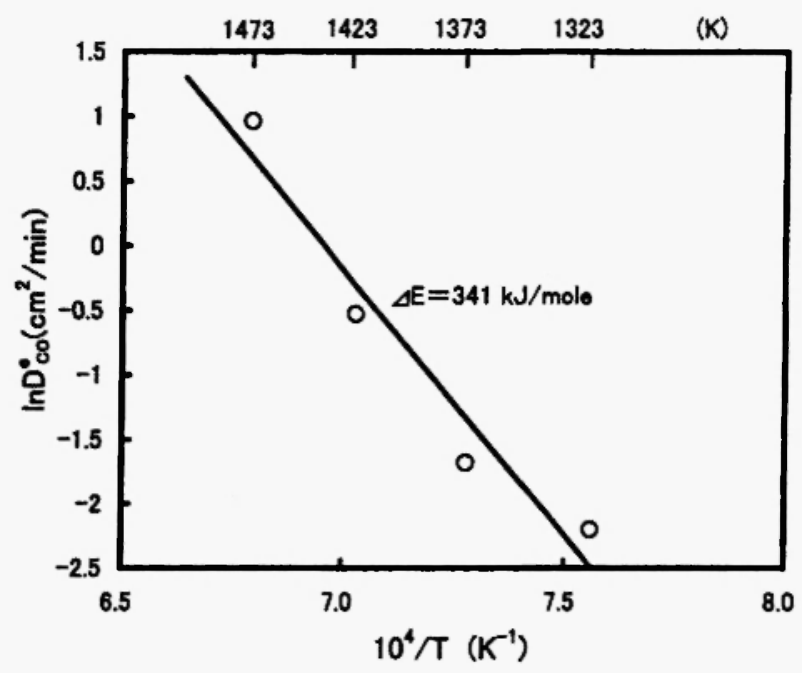

Fig. 8: The relation of $\ln \left(D^{e}{ }_{C O}\right)$ and $1 / T$
The activation energy, $\Delta E$, of the chemical reaction for reduction of zinc oxide sinter by carbon monoxide gas can be calculated from the Arrhenius plot. As shown in the results of Fig. 7, $\Delta E=124 \mathrm{~kJ} / \mathrm{mole}$ is obtained for reduction at low temperature and $\Delta E=146 \mathrm{~kJ} / \mathrm{mole}$ for the high temperature case, respectively. Figure 8 shows the Arrhenius plots with respect to the diffusion coefficient and its activation energy is estimated to be $341 \mathrm{~kJ} / \mathrm{mole}$.

\section{CONCLUSION}

The reduction kinetics including mechanism and reduction rate-controlling step for the zinc oxide sinter commercially used in the zinc electrothermic distillation process has been investigated in the temperature range of 1073-1473 K. The results were analyzed by applying the un-reacted core model. The activation energy of chemical reaction for reduction of zinc oxide by carbon monoxide gas and the overall activation energy of diffusion were estimated. The usefulness of the unreacted core model was found for describing the present experimental data. This kinetic model could be used for a process simulation of zinc smelting, and it would be also interesting to extend the present results to other reduction process of metals at high temperature.

\section{REFERENCES}

1. C.E. Guger and F.S. Manning. Metallurgical Trans., 2, 3083 (1971). 


\section{.}

